\title{
SLUGS AS A CONTROL MEASURE FOR BURDOCKS AT THE PAS, MB?
}

The common burdock (Arctium minus) arrived here in 1961. The first plants were found along the Saskatchewan River at Rall's Island, near The Pas, MB. I have deposited specimens in my herbarium. For many years, this species was scarce. Some 30 years later, another invasive species, A. tomentosum, the downy burdock, arrived in The Pas area and is now becoming common locally. Arctium minus is very infrequent at present, whereas $A$. tomentosum is very abundant and a plague on cattle in the valley west of town. The underbellies of bulls become plastered with the seed heads so that they interfere with the spring cattle breeding.

Arctium tomentosum is now common along the river in Devon Park in town, where it is rapidly taking over the wet clay shoreline. It seems to have no control enemies as yet, although in two gardens in town the large basal leaves are heavily eaten by slugs, which first appeared here in the 1970s. A second likely predator is a Papiapema moth that feeds on the roots during its caterpillar stage. Two such moths came to my mothing lights at night - a recent arrival, though they failed to appear in 2009 and 2010.

The flowers of both burr species are heavily visited by bumblebees (Bombus spp.), as well as a few megachilid bee species.

- Walter Krivda, PO Box 864, The Pas, $M B, R 9 A 1 K 8$

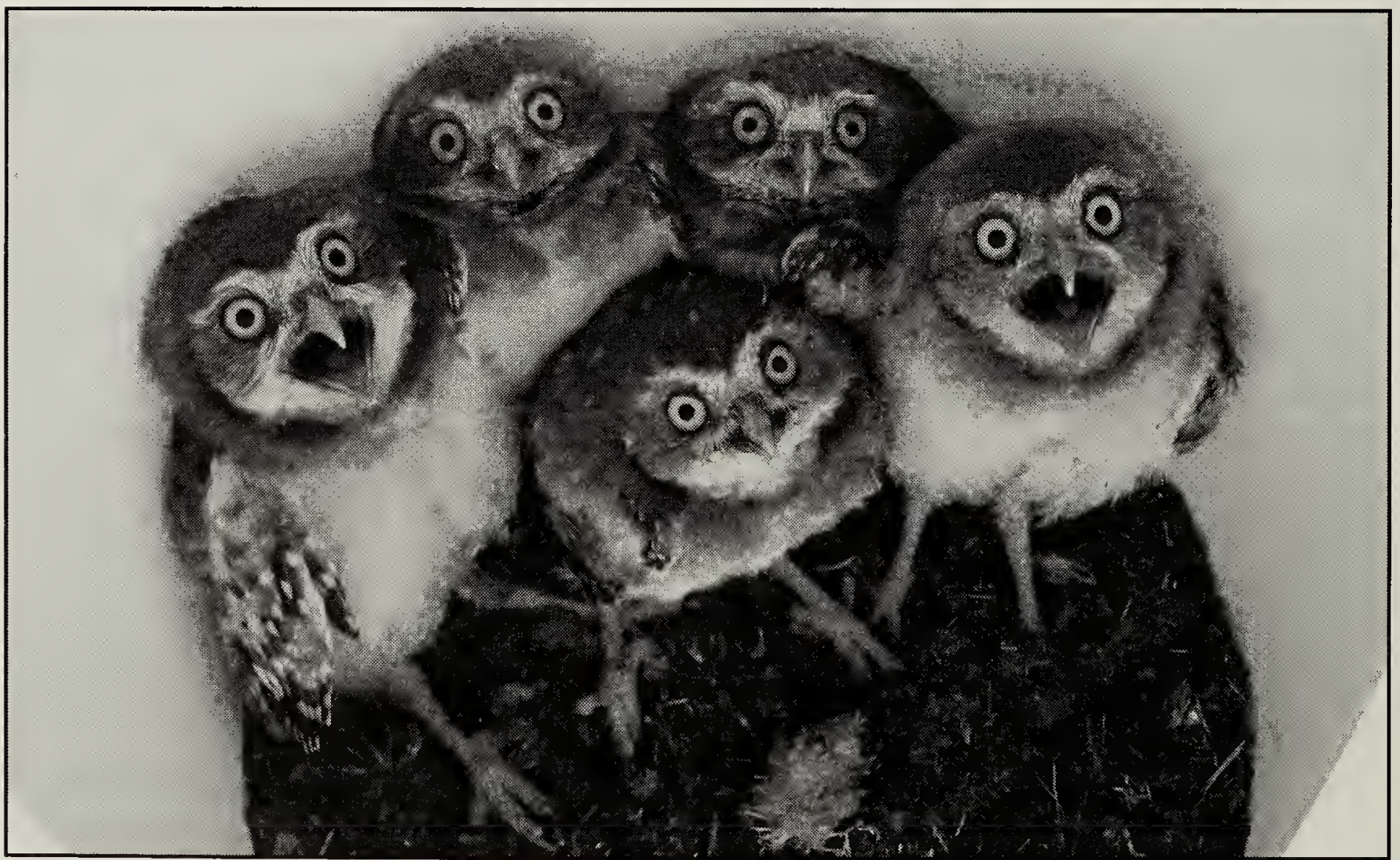

Bucket o' Babes: burrowing owl (Athene cunicularia) chicks huddled at the bottom of a pail. These chicks were captured in 2008 near Rouleau, SK, as part of an ongoing monitoring program.

Adam Crosby 